\title{
Modelling the filling rate of pit latrines
}

\author{
CJ Brouckaert*, KM Foxon and K Wood \\ Pollution Research Group, School of Engineering, University of KwaZulu-Natal, Durban, 4041, South Africa
}

\section{ABSTRACT}

Excreta (faeces and urine) that are deposited into a pit latrine are subject to biodegradation, which substantially reduces the volume that remains. On the other hand, other matter that is not biodegradable usually finds its way into pit latrines. The net filling rate is thus dependent on both the rate of addition of material and its composition. A simple material balance model is presented which represents the faecal sludge as a mixture of biodegradable organic material, un-biodegradable organic material and inorganic material. Measurements made on 2 pits in eThekwini, South Africa, were used to determine parameters for the model. Model predictions were then compared with data from 15 other pits in the same area and filling rate data from previous South African studies, which exhibit a $20^{\text {th }}$ to $80^{\text {th }}$ percentile range of 200 to $453 \mathrm{l} \cdot \mathrm{pit}^{-1} \cdot \mathrm{yr}^{-1}$. These comparisons indicated that the pits studied exhibited relatively low filling rates resulting from orderly disposal practices. The average composition of the pit (COD, biodegradable material and inorganic fraction) changes with age, which will impact on any subsequent sludge treatment process. Pit filling rates are greatly affected by the disposal of solid waste in addition to the faecal material. For the pits studied, the model predicts that the filling time could have been extended from 15 years to over 25 years if all solid waste had been excluded from the pit.

Keywords: Pit latrine, filling rate, biodegradation, solid waste disposal

\section{INTRODUCTION}

eThekwini Water and Sanitation are responsible for the provision of sanitation services in Durban. After the formation of the Municipality in 1999, about 60000 ventilated improved pit (VIP) latrines were inherited from the incorporated local entities. The VIPs in eThekwini are lined single-pits and include the four necessities of a VIP: a pit $1.5 \mathrm{~m}$ deep (or deeper), a foundation and cover slab, a superstructure and a vent pipe with a fly screen (Mara, 1984). After sewerage reticulation had been extended to a number of residential areas and a more formal survey undertaken, it was found that there were 45000 VIP latrines that had reached or were reaching the end of their service life, in that they were completely full. By June 2011, all 45000 VIP pits had been emptied and were once again fully serviceable. A solid waste collection and removal service has been implemented. It is now proposed to empty all the VIPs on a 5-year cycle. In the initial round of emptying, the average age of the pit was approximately 14 years, and many of the pits were fill or overflowing and in urgent need of emptying. The municipality proposed that a 5 -year cycle should be used for emptying since this was possible from an organisational point of view, and most pits are expected to require more than 5 years to fill. In addition, 5 years is the amount of time that a standard pit servicing an average family (5.5 people per household) will receive a volume of material equal to the holding volume of pit; or, in other words, the average pit will fill completely in 5 years if no degradation of pit contents occurs. The cost of emptying a pit, depending on removal method, content disposal location, accessibility of pit, and terrain, ranges between ZAR 300 and ZAR 1250 per pit (Still and Foxon, 2012a). The cost of pit emptying is more closely aligned to the number of pits emptied

To whom all correspondence should be addressed. 푬 +27 31260 1129; e-mail: brouckae@ukzn.ac.za Received 18 September 2012; accepted in revised form 24 June 2013. than to the volume of pits emptied; thus, from an economic point of view, a better understanding of pit filling rates would assist in more cost-effective design of the pit emptying programme.

The four main processes in a VIP are: the filling of the pit, the transfer of water into and out of the pit, biological transformations, and pathogen die-off (Buckley et al., 2008). The pit contains a range of substances, including faeces, urine, anal cleansing material, and general solid waste. The contents of a VIP have an aerobic surface layer, but anaerobic conditions prevail in deeper layers. Thus the exposed surface of pit contents, especially newly added material, will be subject to aerobic biological processes. As the pit contents are covered over and oxygen supply is limited, conditions in the pit become anaerobic, and anaerobic biological processes dominate. The amount of time faecal sludge spends under aerobic conditions depends on the rate at which material is added to the pit, and pit dimensions (Buckley et al., 2008). Sludge accumulation in VIPs and strategies for emptying full pits were the subjects of a recent comprehensive research programme (Still and Foxon, 2012a,b; Still and O'Riordan, 2012).

\section{MATERIALS AND METHODS}

\section{Overview}

A simple material-balance model of the filling and degradation processes occurring in a pit latrine was developed, and compared with field measurements. The model considers the material found in a pit to be divided into two main categories: the so-called 'fine sludge' is that portion that is visually approximately homogeneous, with a maximum particle size of about $1 \mathrm{~mm}$; and a component made up of un-biodegradable household 'coarse refuse' that has a much larger particle size, i.e., plastic bags, discarded cloth and other household detritus. Since no biological transformations occur in the coarse refuse fraction, it accumulates with time in the pit and therefore can 


\begin{tabular}{|c|c|c|c|c|}
\hline \multicolumn{4}{|l|}{ Fine sludge } & Coarse refuse \\
\hline \multicolumn{2}{|l|}{ Biodegradable } & \multicolumn{2}{|c|}{ Un-biodegradable } & \multirow{2}{*}{ Un-biodegradable } \\
\hline \multicolumn{2}{|l|}{ Organic } & Organic & Inorganic (ash) & \\
\hline Fine sludge & & & & Coarse refuse \\
\hline Biodegradable & \multicolumn{3}{|c|}{ Un-biodegradable } & \multirow[t]{2}{*}{ Un-biodegradable } \\
\hline Organic & Organic & Organic & Inorganic (ash) & \\
\hline
\end{tabular}

Figure 1

Fractionation of material in a pit, before and after biodegradation takes place be considered in isolation from the other material in the pit. Therefore, the core part of the model considers only the visually homogenous fine sludge portion. This portion is divided into 3 fractions: biodegradable organic matter, matter that was originally unbiodegradable when deposited into the pit, and un-biodegradable matter formed by the biodegradation process. The originally un-biodegradable material is the unbiodegradable fraction of faecal material and any other fine unbiodegradable material that remains during sampling when coarse refuse is separated out (Fig. 1).

Because of the heterogeneous origin of the material, the model is formulated on a volume basis, to reduce complexities associated with density variations.

Two pit latrines were examined for this study. The pits selected were part of the municipal pit-emptying programme and sampling of the pits was performed in conjunction with the municipal pit-emptying team. The pits were located in the same community (Savana Park) in the eThekwini Municipality, and had very similar user profiles, geography, climate, design and construction. Both VIPs selected were filled to within $0.2 \mathrm{~m}$ of the top of the pit, the reported average number of users of each pit was 7 and the pits were located on slopes. VIP 1 was on the top of a steep slope while VIP 2 was on the hillside. Both pits had the same concrete block construction, $2 \mathrm{~m}$ deep with $1.4 \mathrm{~m}^{2}$ cross-sectional area, and were in approximately the same condition with an intact superstructure. Neither pit had been emptied previously. Samples were collected at the top of the pit, after the top $0.5 \mathrm{~m}$ of material was removed, (0.5 m down), $1.0 \mathrm{~m}$ down and the bottom of the pit, approximately $2.0 \mathrm{~m}$ below the original pit content level. The samples were analysed for total solids, moisture content, volatile solids and COD.

Since there is a great deal of uncertainty about the filling process over the lifespan of the pits, the results from these two pits were compared to less intensive data from a study by Bakare et al. (2012) based on a further 16 pits located in various settlements in the eThekwini area, in order to assess the extent to which the results of this study could be considered typical or anomalous.

\section{Sludge accumulation model}

Consider a volume of sludge which initially consists of $v_{b 0} \mathrm{~m}^{3}$ that is biodegradable and $v_{u 0} \mathrm{~m}^{3}$ that is unbiodegradable. Each $\mathrm{m}^{3}$ of biodegradable material degrades to form $\mathrm{k} \mathrm{m}^{3}$ of new unbiodegradable material. The volume of new unbiodegradable material is represented as $v_{n 0} \mathrm{~m}^{3}$, with initial value $v_{n 0}=0$.

The degradation was modelled as a first-order reaction with

$$
\frac{d v_{b}}{d \theta}=-r \cdot v_{b}
$$

where:

$r$ is the rate constant $\left(\mathrm{d}^{-1}\right)$.

Then, after the material has remained in the pit for time $\theta$, the unbiodegradable material formed by degradation is:

$$
v_{n}(\theta)=k v_{b 0}\left(1-e^{-r \theta}\right)
$$

and the original unbiodegradable material present is:

$$
v_{u}(\theta)=v_{u 0}
$$

The total volume present at age $\theta$ is:

$$
\begin{aligned}
v(\theta) & =v_{b}(\theta)+v_{n}(\theta)+v_{u}(\theta) \\
& =v_{b 0} \cdot e^{-r \theta}+k \cdot v_{b 0}\left(1-e^{-r \theta}\right)+v_{u 0} \\
& =v_{u 0}+k \cdot v_{b 0}+(1-k) v_{b 0} \cdot e^{-r \theta}
\end{aligned}
$$

The ratio of the total volume present to the volume of originally unbiodegradable material is:

$$
\begin{aligned}
\phi(\theta) & =\frac{v(\theta)}{v_{u}(\theta)}=\frac{v(\theta)}{v_{u 0}}: \\
& =1+k \frac{v_{b 0}}{v_{u 0}}+(1-k) \frac{v_{b 0}}{v_{u 0}} e^{-r \theta}
\end{aligned}
$$

The fraction of biodegradable material present is:

$$
\begin{aligned}
\beta(\theta) & =\frac{v_{b}(\theta)}{v(\theta)} \\
& =\frac{v_{b 0} \cdot e^{-r \theta}}{v_{u 0}+k \cdot v_{b 0}+(1-k) v_{b 0} \cdot e^{-r \theta}} \\
& =\frac{\frac{v_{b 0}}{v_{u 0}} e^{-r \theta}}{1+k \frac{v_{b 0}}{v_{u 0}}+(1-k) \frac{v_{b 0}}{v_{u 0}} e^{-r \theta}}
\end{aligned}
$$

Ash content is measured on a mass fraction basis, and is a sub-fraction of the originally unbiodegradable fraction. Assuming that the ash fraction has density $\rho_{a}$ and the remainder of the material in the pit has density $\rho_{o}$, and the volume fraction of ash in the originally unbiodegradable material is $F_{a}$, then the volume of ash associated with volume $v(\theta)$ is $F_{a} v_{u o}$, and mass is $m_{a}=\rho_{a} F_{a} v_{u 0}$. The mass contained in volume $v(\theta)$ is: 


$$
\begin{aligned}
m(\theta)= & \rho_{a} F_{a} v_{u 0}+\left[\left(1-F_{a}\right) v_{u 0}\right. \\
& \left.+k \cdot v_{b 0}+(1-k) v_{b 0} \cdot e^{-r \theta}\right] \rho_{0}
\end{aligned}
$$

The mass fraction of ash is then:

$$
\begin{aligned}
& \frac{m_{a}}{m}(\theta)=\frac{\rho_{a} F_{a} v_{u 0}}{\rho_{a} F_{a} v_{u 0}+\left[\left(1-F_{a}\right) v_{u 0}+k \cdot v_{b 0}+(1-k) v_{b 0} \cdot e^{-r \theta}\right] \rho_{0}} \\
& =\frac{F_{a} \frac{\rho_{a}}{\rho_{0}}}{F_{a} \frac{\rho_{a}}{\rho_{0}}+\left[\left(1-F_{a}\right)+k \cdot \frac{v_{b 0}}{v_{u 0}}+(1-k) \frac{v_{b 0}}{v_{u 0}} \cdot e^{-r \theta}\right]}
\end{aligned}
$$

The fraction of the organic material present that is biodegradable is:

$$
\begin{aligned}
\frac{v_{b}}{v_{b}+v_{u}}(\theta) & =\frac{v_{b 0} \cdot e^{-r \theta}}{v_{b 0} \cdot e^{-r \theta}+\left(1-F_{a}\right) v_{u 0}+k v_{b 0}\left(1-e^{-r \theta}\right)} \\
= & \frac{\frac{v_{b 0}}{v_{u 0}} \cdot e^{-r \theta}}{\left(1-F_{a}\right)+k \cdot \frac{v_{b 0}}{v_{u 0}}+(1-k) \frac{v_{b 0}}{v_{u 0}} \cdot e^{-r \theta}}
\end{aligned}
$$

It is assumed that this ratio will be the same whether expressed in volume, mass or COD units, since the biodegradable and unbiodegradable organic fractions are assumed to have the same density and COD.

The age distribution of material in the pit is determined by the history of when it was deposited and the reaction transformations that consumed or generated it. However, the age distribution of the originally deposited unbiodegradable material depends only on the deposition history, as it undergoes no transformations.

This originally unbiodegradable material in the pit will have a residence time distribution (RTD) density function $f_{u}(\theta)$, where $\theta$ is the age of the material (the time since it was deposited). $f_{u}(\tau)$ is defined by:

$$
f_{u}(\tau)=\frac{d F_{u}(\tau)}{d \tau}
$$

where:

$F_{u}(\tau)$ is the fraction of originally unbiodegradable material which has age $t<\tau$.

The total volume of the originally unbiodegradable material is given by:

$$
V_{u}(T)=\int_{0}^{T} R_{u}(t) d t
$$

where:

$R_{u}(t)$ is the rate of addition of unbiodegradable material at time $t\left(\mathrm{~m}^{3} \cdot \mathrm{d}^{-1}\right)$, and

$T$ is the time since the pit started filling.

The RTD function $F_{u}(\tau)$ is then given by:

$$
F_{u}(\tau)=\int_{0}^{\tau} R_{u}(t) d t / \int_{0}^{T} R_{u}(t) d t
$$

For the case where the rate of addition is constant, $R_{u}(t)=R_{u}$, $V_{u}(T)=V_{u} T$ :

$$
F_{u}(\tau)=\frac{\tau}{T}, \text { and } f_{u}(\tau)=\frac{1}{T}
$$

Equation 5 implies that a volume $d v_{u}$ of originally unbiodegradable material of age between $\tau$ and $\tau+d \tau$ will be associated with a volume $\phi(\tau) d v_{u}$.

Thus the total volume of material in the pit is:

$$
V(T)=\int_{0}^{T} R_{u}(\tau) \cdot \phi(\tau) d \tau
$$

For a constant addition rate this becomes:

$$
\begin{aligned}
V(T) & =R_{u} \cdot T \int_{0}^{T} f_{u}(\tau) \cdot \phi(\tau) d \tau: \\
& =R_{u} \cdot T \int_{0}^{T} \frac{1}{T} \cdot \phi(\tau) d \tau=R_{u} \int_{0}^{T} \phi(\tau) d \tau \\
& =R_{u} \int_{0}^{T}\left[1+k \frac{v_{b 0}}{v_{u 0}}+(1-k) \frac{v_{b 0}}{v_{u 0}} e^{-r \tau}\right] d \tau \\
V(T) & =R_{u}\left[\left(1+k \frac{v_{b 0}}{v_{u 0}}\right) T+\left((1-k) \frac{v_{b 0}}{v_{u 0}}\right) \frac{\left(1-e^{-r T}\right)}{r}\right]
\end{aligned}
$$

Equation 5 applies to the entire contents of the pit at age $T$ since the pit started filling, and can be used to calculate the height of pit contents (given pit dimensions) when the pit has been in use for a time period of length $T$.

In order to establish a profile of age vs. level below the surface, consider the volume with ages between $t$ and $T$ where $0<t<T$ :

$$
\begin{aligned}
& V(t, T)=R_{u} \cdot T \int_{t}^{T} f_{u}(\tau) \cdot \phi(\tau) d \tau \\
& =R_{u}\left[\left(1+k \frac{v_{b 0}}{v_{u 0}}\right)(T-t)+\left((1-k) \frac{v_{b 0}}{v_{u 0}}\right) \frac{\left(e^{-r t}-e^{-r T}\right)}{r}\right]
\end{aligned}
$$

Since material of age $T$ corresponds to the bottom of the pit, Eq. (17) can be used to calculate the level in the pit of material of age $t$. The fraction of biodegradable material at this age or level can be calculated using Eq. (6).

In this form, the model assumes that the feed characteristics and feed addition rate are constant and that biodegradable material all degrades at a single constant rate.

\section{Experimental procedure}

Samples of pit contents from the two Savana Park pit latrines (which will be referred to as the 'reference pits') were collected in May 2010 during the municipal emptying exercise. During pit emptying, it was recorded that approximately $25 \%$ of the contents was nonfaecal matter, a value similar to other studies (Still and Foxon, 2012a,b). Samples were dug out of the vault through the back top slab using rakes and spades. The top layer sample was collected from the very first shovelful taken from the surface of the pit contents, and probably contained some material less than a day old. The depth of the pit was measured with a graduated rod, with $0.5 \mathrm{~m}, 1.0 \mathrm{~m}$ and $2.0 \mathrm{~m}$ noted. When the centre of the pit reached the next marked height, another sample was taken. The emptying process disturbed the layering of the material, and frequently the pit content collapsed around holes as they were dug. While sampling, the emptiers attempted to maintain as much order in the sludge layers as possible. Nevertheless it was estimated that the uncertainty of the depth measurement was approximately $300 \mathrm{~mm}$ for the levels of the middle two samples. This uncertainty in depth did not apply to the top or bottom samples, but it was probable that the sample removed from the bottom of the pit was contaminated by samples from higher up the pit. The samples were screened to remove coarse, obviously non-faecal material, such as plastic bags, cloth and broken glass, which meant that the samples did not represent the refuse content of the material. Samples were 
stored in pre-labelled, sanitised and lined plastic containers with lids.

Analyses were performed according to the Standard Methods for the Examination of Water and Wastewater, $20^{\text {th }}$ Edition (APHA, 1998). The sample solution used for COD is a 2-part dilution. $50 \mathrm{~g}$ of sample is blended and mixed thoroughly and diluted to $1000 \mathrm{~m} \ell$ with distilled water. A 60-m aliquot of this solution is diluted with distilled water to $500 \mathrm{~m} \ell$ for the final sample solution. All analyses were done in triplicate. The mass measurements were recorded to $1 \mathrm{mg}$ precision, and the volume measurements to $\pm 1 \mathrm{m \ell}$. Due to the heterogeneous nature of the pit contents, it is expected that significant differences between samples from within the same layer will exist. To obtain an indication of the average composition of material from each layer, a $50 \mathrm{~g}$ composite sample was prepared by collecting smaller masses of material from different parts of each sample. Data for fresh faeces, from Buckley et al. (2008) and Nwaneri (2009), were compared with the measurements from samples of the surface layer in the pits.

\section{Interpreting experimental data in terms of the model}

The distribution of material in the pit is determined by the entire history of what was disposed into it. This depends on the history of the users' behaviour, about which we have almost complete ignorance. Modelling the process therefore inevitably involves sweeping assumptions, such as considering the rate of deposition of material into the pit and its characteristics to remain constant for the entire period. Furthermore, even if detailed information were available, more detailed assumptions probably would not be particularly useful, since they would only be applicable to the specific pits investigated. In view of these uncertainties, one can only expect a rough correspondence between the model and measured data.

Two issues were evident in the experimental data that could not be directly accounted for in the model:

- The first was the observation that the COD/volatile solids ratio of fresh faeces reported by Buckley et al. (2008) was more than twice that of the surface material. This means that either: (i) non-faecal organic matter disposed of in the pit has a much lower COD than faeces, therefore the COD content of pit sludge is diluted relative to that of faeces; or (ii) that the faecal matter loses a significant fraction of COD in the interval during which it is exposed to air before being sampled; or (iii) the faeces of the users of the pit latrines studied had a lower COD concentration than those in the study by Buckley et al. (2008). Given the semi-solid state of pit sludge, it is believed that a combination of (ii) and (iii) is responsible for the differences observed. Without any way of determining the extent to which the difference was due to a high rate of degradation on the surface, the surface degradation was not modelled in this study. Rather, the characteristics of the material on the surface of the pit (the top sample characteristics) were considered to be the effective feed to the pit.

- The second issue was the fate of water in the pit. The data show that water was not conserved in the pit, and indeed it would be surprising if it were, since the pits are not sealed. There was an exchange of water between the pits and the surrounding soil that could not be characterised from the data in this study. To get around the lack of knowledge about the water movement, the model was compared with the measured compositions on a water-free basis. However,

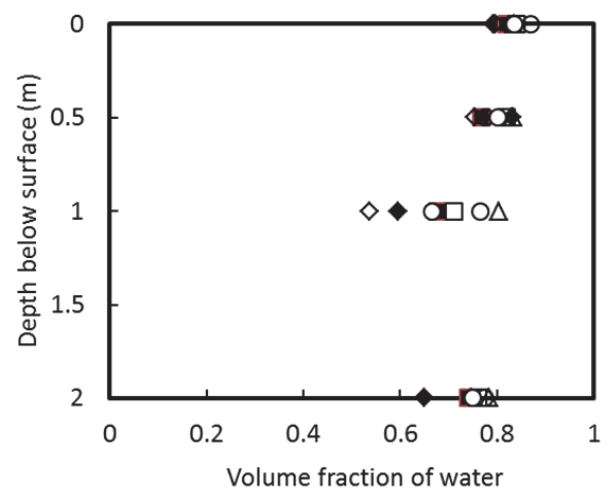

Figure 2

Volume fraction of water

the volume of pit contents must reflect the volume of water, so the modelled volumes of dry material were scaled up using the average measured value for the water content of the pits.

To examine the wider relevance of the model assumptions, 16 sets of less comprehensive measurements (Bakare, 2012) were added to the 2 sets of detailed measurements (this study). Figure 2 shows the volume fraction of water (moisture content on a volume basis) for 7 of the 18 pits that seem to fit the model relatively well.

Since the sampling excluded large objects such as plastic bags, cloth and glass, the volumes of these are not properly accounted for in the model. Thus the model deals only with the fine sludge fraction. However, the disposal of larger objects into the pit is a completely independent process, which needs to be estimated separately on an entirely different basis. During the emptying of the two pits investigated here, the volume of large extraneous material was estimated at $25 \%$ of the total, i.e., $0.7 \mathrm{~m}^{3}$. Over the life of the pit this represents an average rate of $1.296 \times 10^{-4} \mathrm{~m}^{3} \cdot \mathrm{d}^{-1}$, or $47 \ell \cdot \mathrm{yr}^{-1}$ (wet); $2.51 \times 10^{4} \mathrm{~m}^{3} \cdot \mathrm{d}^{-1}$ or $9.2 \ell \cdot \mathrm{yr}^{-1}$ (dry). This represents approximately $10 \%$ of the dry material added to the pit.

\section{Model parameters}

The water content of the pits was taken as $0.8064 \mathrm{~m}^{3} \cdot \mathrm{m}^{-3}$, the average measured value for the two reference pits. COD was assumed to be directly proportional to the volume of organic material (biodegradable or unbiodegradable). The density of the ash was assumed to be $2500 \mathrm{~kg} \cdot \mathrm{m}^{-3}$, and all other material (including water) to be $1000 \mathrm{~kg} \cdot \mathrm{m}^{-3}$, giving $\frac{\rho_{a}}{\rho_{0}}=2.5$.

The remaining parameter values were adjusted by manual trial and error to fit the measured data, and are tabulated in Table 1. Figures 3 and 4 show the fit of the model to the reference pit data. The 'fraction of COD remaining' is calculated as the ratio of the COD measured at a depth to the COD at the surface.

\section{Comparison with field data}

The model derived using data from the two reference pits was compared to less comprehensive data from 16 other pits in the eThekwini area. Of these additional pits, 5 of the 16 corresponded reasonable well to the model trends ('good' pits: Figs. 5 and 6), however the remaining 11 exhibited no discernible trends whatsoever ('bad' pits: Figs. 7 and 8). 
TABLE 1

Fitted model parameter values

\begin{tabular}{|l|c|c|c|}
\hline Description & Symbol & Value & Units \\
\hline Rate of addition of un-biodegradable material (dry basis) & $R_{u}$ & $4.16 \times 10^{-5}$ & $\mathrm{~m}^{3} \cdot \mathrm{d}^{-1}$ \\
\hline Ratio of biodegradable to un-biodegradable material fed & $v_{b 0} / v_{u 0}$ & 3.8315 & $\mathrm{~m}^{3} \cdot \mathrm{m}^{-3}$ \\
\hline Fraction of un-biodegradable material fed that is ash & $F_{a}$ & 0.6748 & $\mathrm{~m}^{3} \cdot \mathrm{m}^{-3}$ \\
\hline Yield of un-biodegradable organic material from degradation of biodegradable material & $k$ & 0.1 & $\mathrm{~m}^{3} \cdot \mathrm{m}^{-3}$ \\
\hline Rate constant for bio-degradation & $r$ & 0.0015 & $\mathrm{~d}^{-1}$ \\
\hline Rate of addition of coarse refuse (dry basis) & $R_{L}$ & $2.51 \times 10^{-5}$ & $\mathrm{~m}^{3} \cdot \mathrm{d}^{-1}$ \\
\hline
\end{tabular}

* The coarse refuse addition rate was estimated separately from the parameter fitting exercise described above.

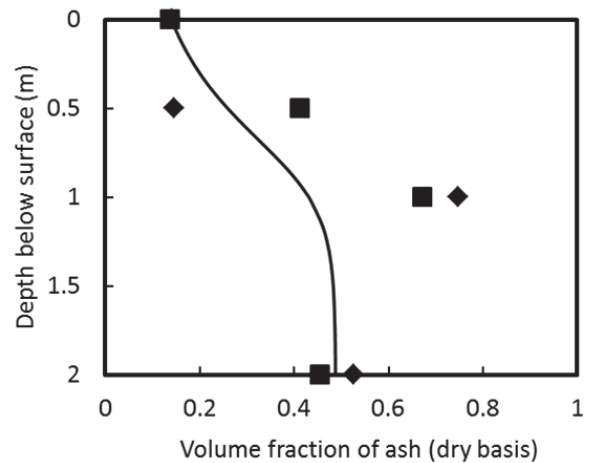

Figure 3

Distribution of ash with pit depth for the reference pits, together with fitted model line

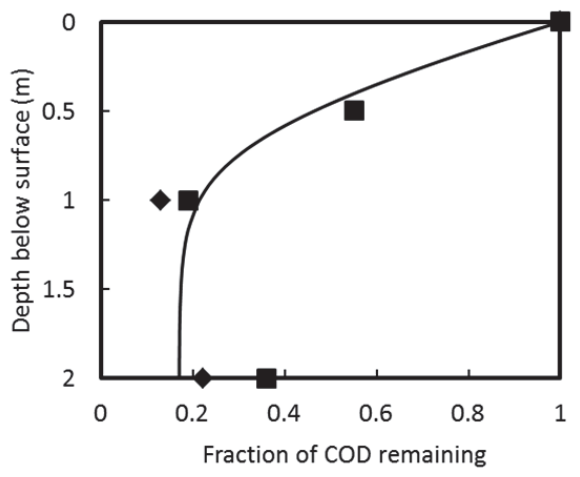

Figure 4

Distribution of COD with pit depth for the reference pits, together with fitted model line

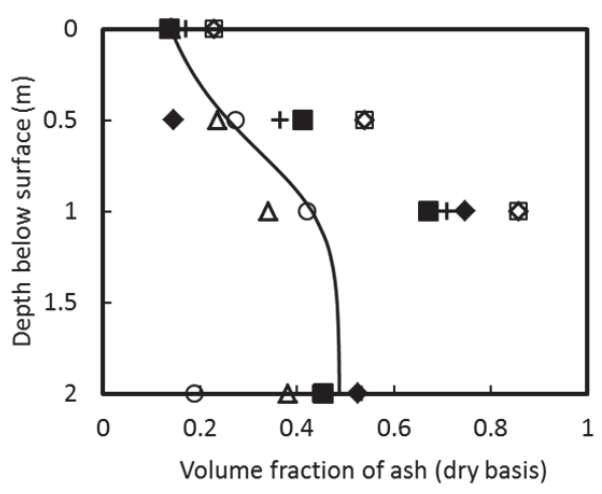

Figure 5

Distribution of ash with pit depth for the 'good' pits

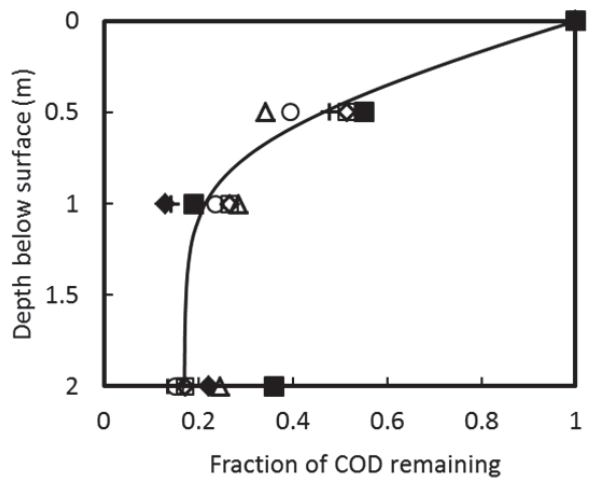

Figure 6

Distribution of COD with pit depth for the 'good' pits

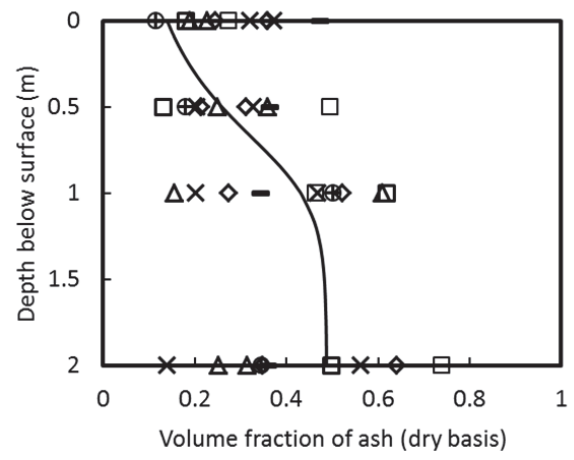

Figure 7

Distribution of ash with pit depth for the 'bad' pits

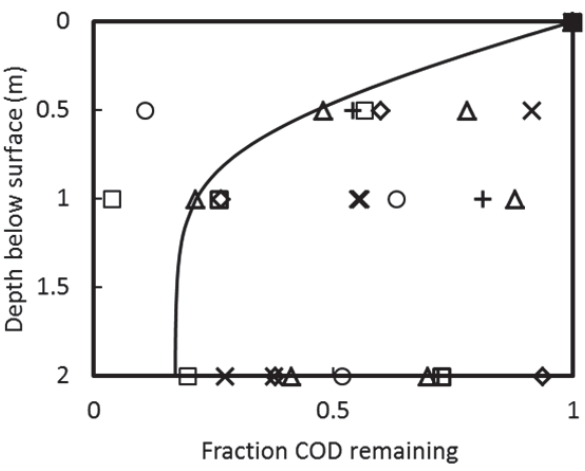

Figure 8

Distribution of COD with pit depth for the 'bad' pits 


\begin{tabular}{|l|c|c|}
\hline \multicolumn{3}{|c|}{ TABLE 2 } \\
\hline \multicolumn{2}{|c|}{ Model feed characteristics } \\
\hline Description & Value & Units \\
\hline Rate of addition of dry material (excluding coarse refuse) & 0.182 & $\ell \cdot \mathrm{d}^{-1}$ \\
\hline Rate of addition of wet material (excluding coarse refuse) & 0.942 & $\ell \cdot \mathrm{d}^{-1}$ \\
\hline Un-biodegradable material in sludge (dry basis) & $21 \%$ & $\mathrm{~m} \cdot \mathrm{m} \cdot \mathrm{m}^{-3}$ \\
\hline Inorganic ash in sludge (dry basis) & 14 & $\mathrm{~m}^{3} \cdot \mathrm{m}^{-3}$ \\
\hline Rate of addition of coarse refuse (dry) & 0.025 & $\ell \cdot \mathrm{d}^{-1}$ \\
\hline Rate of addition of coarse refuse (wet) & 0.13 & $\ell \cdot \mathrm{d}^{-1}$ \\
\hline
\end{tabular}

The filled symbols in Figs. 5 and 6 represent the two reference pits in Savana Park, and the open symbols are for the other five pits.

\section{DISCUSSION}

\section{Modelling assumptions and approximations}

The purpose of developing the pit filling model is primarily to assist municipal planners to formulate strategies for managing low-cost sanitation services based on pit latrines. However, it is necessary to examine its applicability carefully, given its sweeping assumptions and limited fit to the experimental data. It is also necessary to consider the limitations of the data themselves.

Any apparent complexity of the mathematical formulae is in contrast with the simplicity of the concepts that they represent. Essentially the model is based on the obvious consideration that the biodegradable fraction of the material that enters a pit disappears with time, thereby reducing the amount that eventually needs to be removed during emptying. The disappearance is represented in the simplest possible way, as a first-order reaction. Similarly, the simplest possible assumptions represent the feed to the pit - constant rate and composition. The justification for these simplifications is that the uncertainties in the measured data are too great to support anything more sophisticated. Most of the uncertainties appear to be related to what is disposed of into the pits; so, to estimate the removal rate constant, the two reference pits were selected because they were expected to exhibit lower than usual uncertainties in the feed rates and compositions. In extrapolating the model results to other pits, the same reaction rate has been used, because there is no way to determine how it might vary from the data available, and because any uncertainty in the rate is overshadowed by uncertainties in the material fed to the pits.

It may be concluded from the consideration of the measured data that the model showed a reasonable correspondence with a substantial proportion of pits in the eThekwini area (7 out of 18 in the sample considered), but more than half did not fit the model. However, the data for those that did not fit the model showed no discernible trend at all, and may merely reflect unpredictable user behaviour. It is possibly significant that all but two from this 'bad' set of pits had ash contents at the surface that were substantially higher than the reference pits, indicating that the pits may have been used for disposal of much higher proportions of material other than excreta and toilet tissue, and that this may have accounted for the characteristics of the pit samples.

A similar argument applies to water content, since the movement of water into and out of a pit depends on site-specific factors. Since water occupies about $80 \%$ of the pit volume, it does have to be accounted for, but there does not seem to be any better option than using the average value. It should be noted that researchers with experience of pit latrines in Asia and other parts of Africa consider those found in eThekwini to be unusually dry, so the average value used in this study probably needs to be re-considered for other localities.

The assumptions of uniform feed composition and uniform degradation rate over the life of the pit are clearly unrealistic in themselves, but there is no way that they could be improved in practice, and probably no advantage for policy planning that could be derived from a more detailed treatment.

There is good reason to believe that there is a much higher rate of biodegradation of material on the surface of the pit, where conditions are aerobic, than for material that has become submerged. However the measured data do not provide any information which could be used to estimate this. For this reason, the surface material was taken as the effective feed to the pit, ignoring any processes taking place on the surface. As a result, the filling rate cannot be directly related to the actual input but has to be inferred from the level in the pit and the time that it has been in operation. However, data from Still and Foxon (2012b) showed no correlation between filling rates estimated from pit-emptying records and the reported number of users per household, so it appears that there may be no better approach to the problem than the one adopted here.

\section{Parameter values}

The parameters $R_{u}$ and $v_{b 0} / v_{u 0}$ are convenient for the derivation of the model, but are less convenient for relating to field conditions. However the feed to the pit can also be described in terms of the equivalent values in Table 2.

Note that, as previously explained, the model feed composition does not correspond to what users deposit in the pit, because it does not account for biodegradation that occurs at the surface before it gets buried.

\section{Predicted scenarios}

If the model is accepted as the best estimate available for a process filled with uncertainties, the following scenarios illustrate how it might be used to evaluate strategies for designing a sanitation service based on pit latrines. Figures 9 to 11 represent the composition of the fine sludge fraction for the pit contents, to which must be added any coarse refuse disposed into the pit. Figure 9 considers how the volume in the pit will vary with time for various proportions of un-biodegradable material in the feed (these proportions are on a water-free basis, whereas the volume is based on the average water content, as discussed above). The solid black lines (20\%) correspond to the parameter values that fitted the pit data of this investigation. The dotted lines (32\%) correspond to the average surface composition of sludge found for the additional pits that did not match the model (see Figs. 7 and 8). 


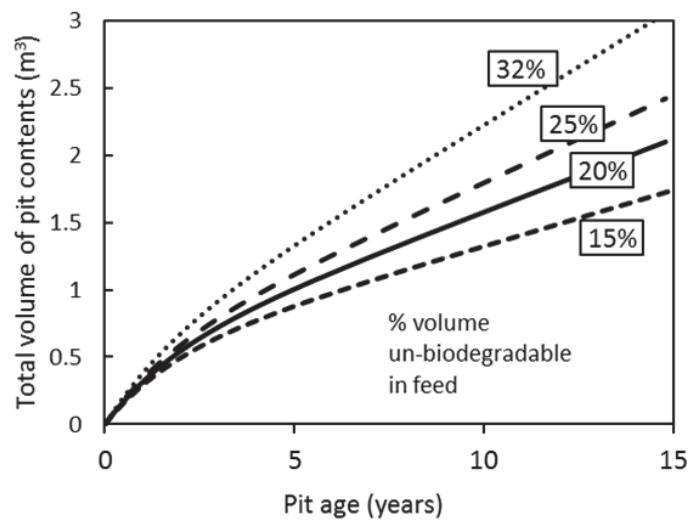

Figure 9

Volume of pit contents for 4 scenarios

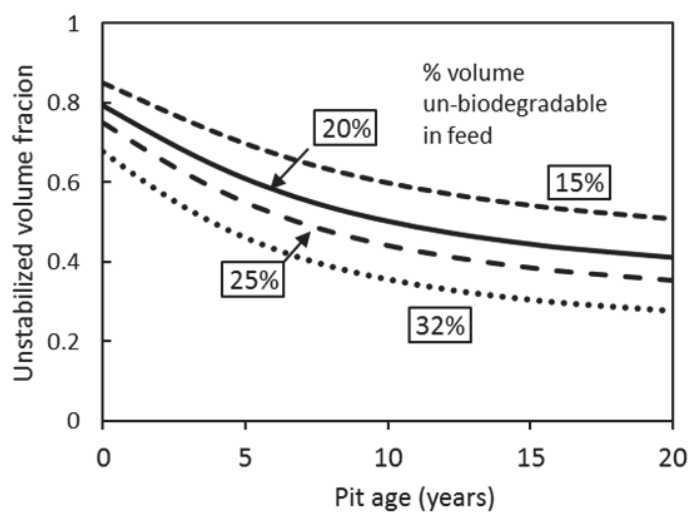

Figure 10

Overall biodegradable content of pit sludge for 4 scenarios

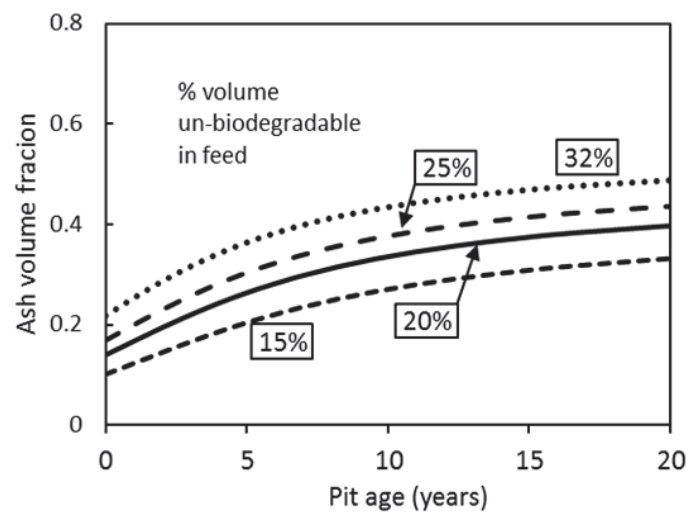

Figure 11

Average ash content of a pit sludge for 4 scenarios

Figures 10 and 11 examine the characteristics of the fine sludge averaged over the entire volume, representing what would be taken out of the pit when emptied, assuming that the stratified contents would become mixed during emptying, and that coarse refuse would be separated out.

These plots indicate that the longer material is left in a pit, the greater the degree of stabilisation of the pit contents when it is exhumed. Using the parameters obtained from the model fitting exercise (biodegradable: un-biodegradable volume addition ratio $=3.8: 1$ ), the average fraction of biodegradable material in accumulated pit contents would reduce from nearly $80 \%$ to less than $40 \%$ over a 10 -year period. Depending on the

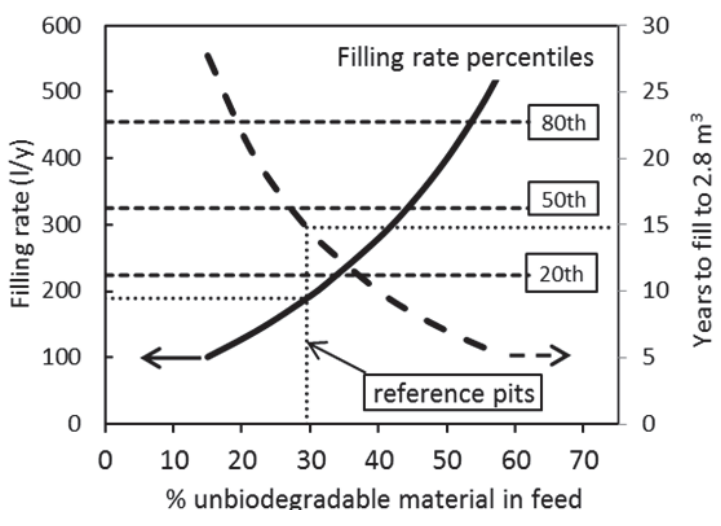

Figure 12

Average filling rates (solid line) and years to completely fill pit (dashed line) vs. feed composition, including coarse refuse

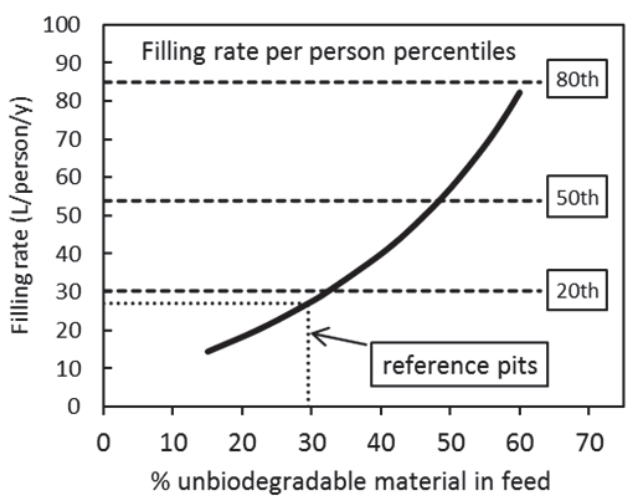

Figure 13

Average filling rates per person vs. feed composition, including coarse refuse

final fate of the pit sludge, this information might be important for designing pit size and emptying frequency to ensure that the exhumed sludge has appropriate characteristics for burial, composting, incineration, etc.

\section{Overall filling rates: including coarse refuse disposal}

Figures 9-11 represent the material left after separating out coarse refuse. However, the volume occupied by this refuse has to be considered when estimating the time to fill a pit. For this purpose, the coarse refuse can be lumped together with the fine un-biodegradable sludge as there is little benefit in considering variations in the fine and coarse unbiodegradable fractions separately. Thus in Fig. 12, the unbiodegradable fraction on the horizontal axis is the combined value. Fig. 12 shows how the fraction of un-biodegradable material in the feed affects the average filling rate over the time required to fill a $2.8 \mathrm{~m}^{3}$ pit serving 7 people. For the average un-biodegradable content of the reference pits in the detailed study (29.5\%) the filling time is $15 \mathrm{yr}$ with a pit filling rate of almost $200 \mathrm{l} / \mathrm{yr}$ (dotted line). Figure 13 presents the model filling rate per person (based on a household of 7). The model curves are compared with the distribution of filling rates taken from a number of studies conducted at different times at a number of sites in South Africa (Still and Foxon, 2012b), represented here by the filling rate percentile lines. 
Figure 13 is included because the data from filling rate studies are usually reported on a per person basis. However, the wider percentile limits for the per-person data appear to confirm that reported numbers of users per pit are very unreliable, and thus only add to the uncertainties. Consequently, the per-pit data of Fig. 12 appears to provide a more reliable basis for design.

It is notable that the reference pits fall below the $20^{\text {th }}$ percentile filling rate. Their selection for this study was based on the fact that the material was easy to sample, because they were clearly well managed pits, with a low proportion of coarse refuse. Orderly user habits probably contributed to the good agreement between model and data for these two pits (i.e. the model assumptions of constant feed rate and composition were approximately valid). However, they were clearly not typical. In contrast, the average un-biodegradable sludge content of the surface fine sludge samples (excluding the household refuse fraction) from the pits that were not well-described by the model was $32 \%$ (Fig. 7). If the household refuse is included, the total un-biodegradable fraction of the surface material would be greater than $40 \%$. From Fig. 12, this set of pits would fall between the $50^{\text {th }}$ and $80^{\text {th }}$ percentiles of the pit filling rate data set, and so is probably fairly typical. The correspondence between the model predictions and available filling rate data is therefore about as good as could be expected.

The model predictions clearly show the impact of increasing the amount of non-biodegradable material in the pit on the filling rate; the reference pits with a low un-biodegradable content addition rate filled $2.8 \mathrm{~m}^{3}$ in approximately 15 years, whereas the more typical pits $\left(50^{\text {th }}\right.$ percentile) fill in approximately 8 years. If the coarse refuse contribution is removed, the filling time predicted for the reference pits is over 20 years. This highlights the importance of keeping coarse refuse out of pit latrines to maximise pit lifespan.

\section{CONCLUSIONS}

Given the uncertainties involved, it seems unlikely that the design of a pit latrine based sanitation service would be driven primarily by the factors described by the model, but rather by considerations of logistics, human resources, cost and the subsequent treatment process. However, the model may be useful to estimate some of the implications of any chosen system design. Nevertheless, the following conclusions may be drawn from the results of the modelling study:

- The quality of the data obtainable from sampling pit latrines is by nature very scattered, such that more sophisticated modelling of the processes in pit latrines is not justified.

- There appears to be a systematic variation of organic content and ash with depth, in that at least 7 of 18 pits showed decrease in COD with corresponding increase in ash content relative to surface samples with increasing depth, using a first-order model of sludge degradation.
- The model predicts that the influence of addition of nondegradable material on the filling rate is significant. Thus, if the intention of the system design is to maximise the life of the pit or to minimise the pit filling rate, an effective solid waste management system must also be implemented within the community - in the case of the reference pits the pit life could be extended from 15 years to over 20 years.

- The average biological stability of the pit sludge increases with time. Pit dimensions and emptying frequency may be designed around the required stability of the sludge when the pit is emptied.

\section{ACKNOWLEDGEMENTS}

The authors thank the London School of Hygiene and Tropical Medicine (which received a grant from the Bill and Melinda Gates Foundation), the South African Water Research Commission, eThekwini Water and Sanitation Services and Partners in Development (Pty) Ltd for financial and technical support of this work.

\section{REFERENCES}

APHA (AMERICAN PUBLIC HEALTH ASSOCIATION) (1998) Standard Methods for the Examination of Water and Wastewater. $\left(20^{\text {th }}\right.$ edn.). American Public Health Association, Washington DC.

BAKARE BF, FOXON KM, BROUCKAERT CJ and BUCKLEY CA (2012) Variations in VIP latrine sludge contents. Water SA 38 (4) 479-485.

BUCKLEY CA, FOXON KM, BROUCKAERT CJ, RODDA N, NWANERI C, BALBONI E, COUDERC A and MAGAGNA D (2008) Scientific Support for the Design and Operation of Ventilated Improved Pit Latrines (VIPs) and the Efficacy of Pit Latrine Additives. WRC Report No. TT 357/08. Water Research Commission, Pretoria.

ETHEKWINI MUNICIPALITY WATER AND SANITATION UNIT (2011) Draft Water Services Development Plan Version 19. eThekwini Municipality, Durban.

NWANERI CF (2009) Physico-Chemical characteristics and biodegradability of contents of Ventilated Improved Pit latrines in eThekwini Municipality. MSc dissertation, School of Biological and Conservation Science, University of KwaZulu-Natal, South Africa.

ETHEKWINI MUNICIPALITY (2011) eThekwini Municipality Integrated Development Plan, 5 Year Plan: 2011 to 2016, 2011/2012 Plan, adopted 15 June 2011 (ver. 003). eThekwini Municipality, Durban.

STILL D and FOXON K (2012a) Tackling the Challenges of Full Pit Latrines, Volume 1: Understanding sludge accumulation in VIPs and strategies for emptying full pits. WRC Report No. 1745/1/12. Water Research Commission, Pretoria. ISBN 978-1-4312-0291-1.

STILL D and FOXON K (2012b) Tackling the Challenges of Full Pit Latrines, Volume 2: How fast do pit toilets fill up? A scientific understanding of sludge build up and accumulation in pit latrines, WRC Report No. 1745/2/12 Water Research Commission, Pretoria. ISBN 978-1-4312-0292-8.

STILL D and O'RIORDAN M (2012) Tackling the Challenges of Full Pit Latrines, Volume 3: The development of pit emptying technologies, WRC Report No. 1745/3/12. Water Research Commission, Pretoria. ISBN 978-1-4312-0293-5. 